\title{
Chapter 14 \\ Invisible or Powerful? Ageing \\ in a Mediatised Society
}

\author{
Annika Bergström and Maria Edström
}

\subsection{Introduction}

Freedom of expression and freedom of information are core human rights that connect the concept of capability with the role of the media in society. In order to be able to live your rights and make choices to achieve your personal goals, you need to be informed, to have a voice, to be listened to and to have the opportunity to engage in society, regardless of age. The media influences the public agenda, what we think about, and what we believe is important. Images and stories in the media about older adults affect the ideas about ageing that circulate within a society, and these affect how older people are perceived. The media also significantly involves interaction and communication with family, friends, the authorities and their services. The intersection of ageing, the media and capability can therefore be found at all levels of society, from the individual to structural levels, and is closely related to ageism.

The capabilities approach formulated by Amartya Sen (1985), and further developed by Martha Nussbaum (1997), is concerned with equality and the concepts of justice and injustice, arguing that people are entitled to a certain level of resources. The concept captures what individuals are able to do and to be, but also sets the preconditions for resources such as laws and regulations, social security, the labour market, healthcare and norms surrounding ageing. Capability includes preferences, such as what an individual values when it comes to what to have, who to be and what to do. A person should have free choice to act in order to achieve his or her

\footnotetext{
A. Bergström · M. Edström $(\bowtie)$

Journalism Media and Communication (JMG), University of Gothenburg,

Gothenburg, Sweden

Centre for Ageing and Health - AgeCap, University of Gothenburg, Gothenburg, Sweden

e-mail: annika.bergstrom@jmg.gu.se; maria.edstrom@gu.se
} 
goals, which in turn also means having the resources to achieve valuable goals, and the ability to understand what resources one needs to achieve them.

The most relevant aspects of capability in the context of the media relates to Nussbaum's (1997) dimensions of capability, such as using the senses and imagination, feeling love and compassion, being able to reflect critically upon life choices, affiliations with others, and the ability to laugh, enjoy and play. Most important, perhaps, is having the opportunity and ability to control one's environment, to be able to participate effectively in the political choices that govern one's life, and freedom of expression, which in turn is closely related to the resource concept of capability.

In this chapter, we address the relations between ageing, the concept of capability, and the media and communication studies from the perspectives of (1) language and representation relating to how media content is made up with regard to what is communicated, how the content is framed and who is present in the media, and (2) media use and engagement, especially on digital platforms.

\subsection{Living in a Mediatised World}

Most of us live in a mediatised society, where much of our time is spent with media, often in front of different screens. Using and producing media is an important part of most people's lives, and the demand on citizens to critically embrace the media and information is constantly increasing. The process of the media intertwining with people's lives and with societal functions is well captured by the theory of mediatisation. This is a theoretical framework highlighting how the media shapes, maintains and changes practices and ideas in society at large and in the domestic contexts of everyday life (Hjarvard, 2013; Lykke Christensen, 2017).

A mediatised society affects both people and society at the macro, meso and micro levels (Trappel, 2019). At the macro level, implementation processes to access the media and its content can have implications for a person's choices and life chances. Policies, subsidies and regulations impact upon the actions of organisations and individuals. At the meso level, commercialisation of the media business, global monopolies and structural inequalities affect the opportunities of individuals to raise their voices and to participate in a mediatised society. At the micro level, individual factors such as socio-economic prerequisites are important for understanding the relation between capability and the media, but also factors such as the functions of the media and individual motives to engage are crucial for understanding media use and engagement. The consequences of inequalities are expressed, for instance, as skewed news representation, digital divides and knowledge gaps, which create unequal life chances (Trappel, 2019).

Nicholas Garnham (1997) applied Sen's capability approach to communication during the 1990s, and this was recently developed by Nick Couldry (2019: 48-49) 
to a set of functioning that we all value in relation to the media and communication:

- Not being harmed/humiliated or misrepresented through the media

- Basic access to media resources

- Opportunity to be in some broad sense represented as a type

- If one wants to speak, the opportunity to have a voice.

Relating this to ageing and older adults, two main tracks can be pointed out: (1) the media as a set of institutions that influence the public agenda and notions of ageing and older people, and how older people are represented and perceived in society, and (2) the media as tools for communication and interaction, both within close relationships and in the public sphere. Based on the concept of mediatisation, the point of departure is that the media is being simultaneously embedded in the wider society and in the lifeworld of individuals (Hjarvard, 2017).

It is of great importance to emphasise the heterogeneity within the group of older adults. How we age in society depends on socio-economic factors as well as ethnicity, gender and spatialities (rural/urban, home/work) (Torres, 2001, 2019; Westwood, 2019). Inequalities tend to increase throughout the life course, with educational level as one key component of the ability to live a long life (Seeman et al., 2008), and intersectional perspectives are called for by many scholars (Westwood, 2019: 4). As researchers of ageing, it is important to be aware of the normative assumptions that are embedded in our minds, in the research literature and in the media. In a mediatised world, media competence then becomes crucial, regardless of who you are.

\subsubsection{Media and Information Literacy in a Mediatised Society}

In most societies, a broad spectrum of civic engagement is considered crucial for maintaining the democratic system (McLeod et al., 1999; Putnam, 1993; Shaker, 2014). A key function of the media is to provide people with the information they need to be free and self-governing (Kovach \& Rosenstiel, 2014). In this regard, the capability concept is clearly related to the concept of media and information literacy (MIL), which takes its point of departure in the more general concept of literacy.

It is through these skills of reading and writing that those who are literate are able to participate more fully in society, both economically and socially, and are able to understand and exert a higher degree of control over everyday events. (Nutbeam, 2008: 2072)

MIL is about the ability to read media language in a broad sense, about consciousness of the social, political, cultural and economic factors behind media business and the messages distributed by the media. Both UNESCO and the European Parliament state that MIL is a necessary key competence in the information and communication society and crucial for democracy (see also Livingstone, 2008). Fundamental literacies, as expressed in Article 19 of the Universal Declarations of Human Rights, should thus be seen as a common good (Carlsson, 2010: 15, 73; 2015; Petäjä, 2006). MIL includes all kinds of media texts: the written word, as well 
as audio and visual expressions distributed through channels that carry all these kinds of texts, which includes all situations where messages are communicated through any technical distribution channel (Buckingham, 2003).

Media and education scholar David Buckingham (2003) presents four different types of knowledge as a framework for media literacy:

1. Production: related to the media as produced with a certain purpose, knowledge about who owns, controls, distributes and is reached by and heard in media texts. It also includes creating and reflecting upon media content.

2. Language: the production of meaning in the media. What effects follow from certain messages with a certain style, genre etc.

3. Representation: the media constructs reality. Media texts are chosen as representatives of people, groups, events and histories. This is about understanding and is related to depictions of stereotypes.

4. Audience: how different groups in society use different media, and how they interpret media messages and the effects of this. It is also about people's ability to reach out through the media.

There are several other, somewhat similar, ways to capture the general aim of MIL, which are all related to the connection between the mediatised society and capability. Livingstone (2008) relates the concept of MIL to democracy, participation and active citizenship, and also to the ability to create an opinion and to make one's voice heard. Other researchers present this in slightly different ways (Perez Tornero $\& \mathrm{Pi}, 2011$; Potter, 2005), but basically researchers gather around the concepts suggested by Buckingham (2003).

In the context of capability, we would like to address two main areas drawn from Buckingham's framework. One area concerns language and representation, and relates to how media content is made up with regard to what is communicated, how the content is framed and who is present in it. The other area concerns engagement in the media from the individual's point of view: producing and using media and media content.

\subsubsection{Media Research-An Emerging Field}

Before turning to specific cases of media and capability, something needs to be said about media research at an overall level. Media studies derive from several different disciplines, and can be understood as a multidisciplinary field. The origins include, among others, sociology, political science, humanities, literature and organisation theory.

The media is studied from several perspectives and by means of several methods. It is common - but not necessary - to separate studies of production, content and use. Production studies include media organisations, regulations and policies and how different kinds of media and information content are created. There are, for instance, studies on news value and the roles of journalists. Content studies reveal what is actually published, what characterises different types of content from 
aspects such as frames and representation. Studies of media use and consumption map in different ways how the audience actually makes use of content. Here it is worth mentioning that media research is an emerging field, and older age groups have often been neglected within it.

Media studies use both quantitative and qualitative methods, sometimes mixed. The quantitatively performed studies are usually based on either survey data with editors, journalists or audience members, or on systematic content analysis measuring numbers of issues, actors or other aspects of what is published or included in different policy documents. Qualitatively based studies emphasise the individual worker or user, his or her interpretation of working conditions, storytelling or, from the user's point of view, the role of the media and content in everyday life, the actual meaning of content and the like. Qualitative content analyses are based on in-depth reading of specific content in order to reveal meaning, and sometimes to read between the lines.

We will now turn to two of the previously mentioned fields, where we find the strongest correlations between media research, the concept of capability and ageing: the presentation and representation of older adults in media content and the media as a tool for communication, interaction and engagement.

\subsection{Language and Representation}

Media representations have an impact on how we understand the world. News media have an agenda-setting function in the sense that they draw our attention to certain topics and areas, and therefore contribute to shaping our ideas and opinions on different topics (Weaver, 2007). If you do not have a voice and are not part of the media narratives, you become more or less invisible in society. Therefore, the symbolic power of the media is a key concern for many researchers. Media scholar Nick Couldry claims that we have a growing crisis of voice across political, economic and cultural domains (Couldry, 2010). This is not primarily an issue at the individual level, but something for groups to address. Social representation is considered an important part of democracy, especially in the political sphere. The representation and presence of older persons in the media can thus be seen as a proxy for their communication rights and political rights.

At a general level, the media is interested in what is new and what the next generation has to say. In a similar way, media research tends to focus on new media trends and the impact of technology. Media scholar John Hartley even talks about juvenation, the way in which the media communicates with youth (Hartley, 1998). Similarly, media research tends to have a focus on new trends, new media platforms and expressions. This is of course a contributing factor when thinking about why there is a void when it comes to the role of ageing and health in the field of media and communication research.

Media images of ageing mainly refer to older people in a simplified manner, depicting retired people as one homogenised group. The focus is mainly on 
chronological age, and media representations are often stereotyped into two polarised categories: the active golden age (advertising) or the frail, helpless older person (news). The problem with this is that the diversity among older adults becomes invisible, when in fact the expanding group of older adults contains large variations of lived experience, with regard to health, functionality, socio-economic situation and ethnic background.

As more of us live longer and remain healthier, the media and surrounding businesses have an emerging interest in older age groups. Within the advertising industry, there is a clear interest in resourceful, healthy older people, often referred to as 'golden agers' (Bai, 2014). The media interest in older age groups often derives from a consumer perspective, aiming for the 'grey market' with a focus on agelessness and successful ageing. This is in strong contrast to the news media depictions of frail older persons as voiceless and facing problems of declining health (Lundgren \& Ljuslinder, 2011; Nilsson \& Jönsson, 2009; Wien, 2003).

These stereotyped mediatised images of ageing have an effect on all of us and may limit our ideas about ageing and what it means to grow older. The negative attitudes and tendency to undervalue older people also exist among older people themselves, having negative effects on older individuals' self-evaluation and functioning (Coudin \& Alexopoulos, 2010). Negative stereotypes of ageing seem to be very resilient (Levy et al., 2015; Gullette, 2017) and have existed for a long time (Ng et al., 2015).

It is evident that a positive self-perception of ageing tends to increase longevity (Levy et al., 2002). Stereotyped images of ageing and the lack of representation of older people in the media, on the other hand, can be seen as a hindrance to capability, since stereotypes are built on prejudice that may lead to ageism and discrimination (see Butler, 1969; Gullette, 2017; Katz, 2001; Schonfield, 1982). Ageism limits older people's capabilities and the media may confirm, enforce or challenge ageism. The lack of older people in the media can be seen as a form of symbolic annihilation, a term coined by sociologist Gaye Tuchman (1978) to describe the lack of women in the news. The visual patterns in the media are gendered, older women are even more invisible than older men, and the media seems to promote gendered ageism (Edström, 2018; Kokkinakis et al., 2018).

However, media effects are not easy to pin down, because there are several factors contributing to our understanding of the media and the opportunity to make individual interpretations of its symbolic meaning. For example, some studies indicate that older women are negotiating and contesting the stereotyped images of ageing by choosing to dress, act and behave more in accordance with their own life experiences (Dolan, 2015; Gullette, 2017; Lykke Christensen, 2017; Twigg, 2013; Twigg \& Martin, 2015). This is just to emphasise that media effects and their impact are no magic bullet; it is a complex process depending on a web of circumstances ranging from micro to macro levels.

However, when the media coverage of ageing and older adults is too simplistic, and passive or negative images of older adults and ageing circulate widely in the news, this may lead to wider implications for society. If the media does not give older adults a voice, age discrimination in the workplace and elsewhere might seem 
natural. And if news media keep reporting negatively on ageing, elderly care and the situation of older adults, people might internalise these negative views with consequences such as recruitment problems in the field of geriatrics.

How we speak and think about ageing affects not only interpersonal relationships, but also policymaking and decision-making. The American organisation Frame Works Institute has produced both reports and toolkits to reframe communication on ageing and ageism (O'Neil \& Haydon, 2015; Sweetland et al., 2017). The aim is to shift the mind-set so that ageing can be seen as a normal and continuing process and to address the negative attitudes towards it. This will be a long-term struggle, as the coronavirus pandemic has made even more clear. The pandemic has reinforced all kinds of inequalities, not least those based on age. We will therefore take the opportunity to reflect upon ageism in the media during Covid-19.

\subsubsection{The Case of Media Ageism and Covid-19}

In 2020, the world suffered from the global Covid-19 pandemic, which caused deaths, tragedies and lockdowns in many countries. It also changed how older people were treated. Since the virus has struck hard among older sections of the population, many countries started to develop a public discourse of people aged $70+$ as one homogeneous group, a message that was reinforced by the media. As the first studies of the media coverage of Covid-19 emerge, it becomes more evident that the media is reinforcing ageism. A Spanish study of 501 headlines related to older adults and Covid-19 confirms the presentation of a homogeneous group associated with negative representations and death (Bravo-Segal \& Villar, 2020). A study of Swedish newspapers also confirms the representation of people aged $70+$ as a homogeneous group, and the manifestation of an 'us vs. them' mentality regarding older people (Häggkvist \& Rosvall, 2020). During spring 2020, the hashtag \#BoomerRemover was used on social media to discuss whether the purpose of Covid-19 was to remove an overload of older people from the population, a mindset that can be seen as yet another manifestation of ageism (Meisner, 2020). At the same time, others, such as the United Nations Secretary General, tried to counter age-related stigmas and the divisions between age groups that they reinforced (Meisner, 2020; United Nations, 2020).

The many ageist remarks and discussions have raised concerns among geriatrics and gerontologists that the pandemic is magnifying prejudices based on age: '... there has been a parallel outbreak of ageism' states Liat Ayalon and research colleagues in an editorial (Ayalon et al., 2020: e49). Ayalon and colleagues use examples from social media and the press in various countries to argue that the public discourse is reinforcing barriers in already age-divided societies. The authors call for other measures than chronological age to be used when assessing risks and medical care, that special measures are taken to safeguard the human rights of those who are most likely to be classified as vulnerable and to encourage solidarity between generations (Ayalon et al., 2020; Ayalon, 2020). 
The Frame Works Institute has again, in the light of Covid-19, called for changes in the way we think and talk about ageing by appealing to the value of justice, addressing ageism and rating a sense of solidarity as well as urging care in the use of 'othering' terms (Kendall-Taylor et al., 2020).

The Covid-19 pandemic is just one example of where the media might reinforce certain discourses about ageing. It could of course also counter or challenge existing ideas of older people as a homogenous group that needs to have separate restrictions. It is yet to be seen whether the media will act on the ageism of which it seems to be a part. 'In the meantime, although we cannot control the year we were born, we can control how we think about, treat, respect, and empathize with each other across generations, in solidarity - especially in a time of crisis' (Meisner, 2020: 5).

\subsection{Media Use and Engagement}

Engagement in the media can be understood both from the perspective of undesired differences in information and knowledge resources, and from the perspective of getting involved with people and society through media content and content production. Information differences are related to media use generally, and to news consumption habits specifically. Since the 1970s, media scholars have gathered evidence of knowledge differences between different groups in society, differences that may affect societal and political engagement. Information distributed through the media was found to have great impact on knowledge levels, and media use contributes to creating knowledge gaps (Kwak, 1999). The theoretical concept of knowledge gaps has been somewhat reformulated to include motivation to acquire information in the knowledge domain under study. Gaps arise and widen when there is a difference in motivation among population segments (Ettema et al., 1983).

There is a continuously growing amount of information and services on the Internet, and digital skills have become a vital resource in contemporary society. The majority of research in this area demonstrates that there are links between social exclusion and digital engagement. It also seems that groups with limited access to information tend to be further marginalised as computer and Internet skills become more and more important (Hargittai \& Hinnant, 2008; van Deursen \& van Dijk, 2014).

Just as with many other forms of media technology, the Internet was unevenly distributed from its beginnings in the early 1990s. There have been so-called digital divides between groups in societies, countries and regions ever since (Hargittai \& Hinnant, 2008; Norris, 2001; Tsatsou, 2011). The significance of digital inequalities is clear across a broad range of individual-level and macro-level domains, including life course, gender and class as well as in healthcare, politics, economic activity and social capital (Robinson et al., 2015). One of the most important factors explaining inequalities in access and use is age (Bergström, 2017), and it has been proven that older adults perform less well than younger generations with regard to Internet skills (van Deursen \& van Dijk, 2014). 
Digital inequality affects the potential to shape one's life chances in multiple ways. Personal computers and the Internet have meant increased opportunities for communication, information-gathering and entertainment and for accessing different public and commercial services (Carpenter \& Buday, 2007; Dickinson \& Gregor, 2006; van Deursen \& Helsper, 2015). But the issue of digital inequality extends far beyond access and skills. The continuous development of the digital society strongly and increasingly affects those who for different reasons remain outside. The Internet has become important both for personal reasons and for societal involvement. 'It has become clear that reliable Internet connection and access to computing devices is not a luxury but rather, a social need and a public utility' (Treré et al., 2020: 2).

Internet activities in such areas as financial matters, entertainment, shopping, information-gathering and news offer opportunities that could be beneficial, particularly for seniors with limited mobility (Reisenwitz et al., 2007). Using a home computer, tablet or smartphone can enable older adults to continue living independently in their own homes, and communication technologies are said to have the potential to minimise social isolation (Boulton-Lewis et al., 2007; van Deursen \& Helsper, 2015). The Internet has been widely recognised as a valuable tool for acquiring healthcare information and services (Rains, 2008). Furthermore, older adults are frequently heavy users of civic services in the Nordic countries, and the same time many service providers are digitalising their range. It is worrying that older people's lack of Internet access and skills limit their engagement with online services that are highly significant to them (Robinson et al., 2015).

The use of information and communication technologies (ICTs) have the potential to enhance quality of life by sustaining independent living and providing opportunities for greater democratic and societal engagement (Boulton-Lewis et al., 2007; Loos, 2012; Obi et al., 2013; Rains, 2008). In an interview study, older adults clearly expressed feelings of empowerment connected with media use, and being able to control media technology was also linked to social positioning and identity (Givskov, 2017). But developments in the media environment with regard to communication and interaction have posed a challenge for many older adults, who have only been confronted with digital media technologies late in their lives; hence, they are generally late adopters (Lykke Christensen, 2017).

It is evident that older adults constitute a group that could both benefit from digital content and services and to a large extent are hindered from engaging with these due to lack of access, skills and motivation to use them. Although this applies to the whole group of older adults, it is especially evident among the oldest. Public authorities and IT-related commissions have struggled with these inequality issues for decades. The problem has been visible since the mid-1990s, but there have been very few proposals for concrete measures. This is partly a result of power diffusion within the field. Many different actors have different responsibilities for digital infrastructure, tools, accessibility etc. Over time, the influence of global actors over local contexts has increased. The complicated issue of responsibility makes decision-making and accountability difficult.

The issues raised in this section have become highly topical during the Covid-19 pandemic. Most everyday activities have been restricted, and online activity has 
become the new reality. Information flow is one of several key factors in fighting the pandemic. The Internet also enables isolated individuals to maintain social contact remotely with family, friends and acquaintances, and provides access to different kinds of entertainment and pastimes. Being an offliner in such difficult circumstances of physical distancing could lead to a dual sense of exclusion. There is a significant risk of ageism if society focuses only on digital events as a means of social participation during the pandemic (Seifert, 2020).

A recent Israeli study of older adults during the first phase of the pandemic shows that the ability to adjust their Internet use and to make use of digital technology for coping with stress-related issues is somewhat unclear and uncertain. The older adults who participated in the survey report significant increases in Internet use during the pandemic, particularly different chat software, in a manner that resembles that of young adults. They also increased their use of applications for shopping, financial management, medical support and newspaper reading. Online activities related to recreation and wellbeing, such as playing digital games, downloading films and music, writing blogs etc., did not increase during the study (Nimrod, 2020).

\subsection{Conclusions: Opportunities and Challenges Within the Intersection of Ageing, the Media and Capability}

To conclude, when reflecting on the relationship between ageing, the media and capability, democracy becomes the common thread, with freedom of expression and freedom of information emerging as core human rights. In order to live your rights and be able to make choices to achieve your own goals, you need to be informed, have a voice and have the opportunity to engage in the things you find valuable. As outlined above, it is not self-evident that older age groups can raise their voices either inside or outside the media or how they can make sure that their voices are heard. Nor is it clear what implications exclusion from mediatised society will have for different groups of older adults. This final section of the chapter will reflect upon different aspects of this matter, addressing challenges and suggesting ways forward.

This review of language and representation, and of engagement with the media, clearly shows that the mediatised society affects people at the micro, meso and macro levels. Inequalities exist regarding both representation in, and engagement with, the media, and age is a significant factor. It becomes something of a paradox that a growing group of older adults, whose lives would benefit greatly from becoming mediatised, are largely neglected or left out of the media society.

At a micro level, as a person grows older within a society, the media can be a tool for enhancing their capabilities, but it can also be perceived as hindering a good life. Skewed or non-representative content, or a lack of space for expressing thoughts and opinions might make you feel incapable, and may also make others feel that you are incapable. In relation to media use, especially digital media, the question of choosing not to have or to use media becomes crucial. If technology and its 
applications are perceived as awkward and/or difficult to access, they become obstacles rather than useful tools. Furthermore, it is not self-evident that each individual knows what resources are needed, how to get them or how to use the available resources.

Media and information literacy (MIL) is therefore key for improving the capabilities of older adults. The framework of MIL is useful for understanding the role of the media in society as a means of enhancing capability. It has primarily been used in contexts involving younger people and is commonly related to school and education. We would suggest, however, that the MIL concept be adopted in future research within the field of ageing, the media and capability, since it combines core aspects from various fields. Several perspectives within MIL are very useful in relation to ageing and capability, not least in the field of health literacy and digital devices.

At the meso level, critical issues relate to who should be accountable for media content and the lack of older adults' voices or diverse stories about them, and the responsibility of media corporations to target and reach audiences of all ages is crucial. In our opinion, the media industry needs to take into account how media content can be more inclusive, in order to counter ageism, address issues relating to diverse conditions for ageing, and take into account that there is more to ageing than chronological age. In the case of the Swedish media context, as in many countries, this is primarily something that can be achieved by means of self-regulation measures.

Media corporations and platform providers also need to include ideas for how media technology can be developed in relation to cognitive loss or disabilities. This aspect can be considered especially important for public-service media and could be a topic for regulators and self-regulators to address. Much of the responsibility for development and change is in the hands of commercial actors in contemporary society, and this is also true for the media sector. Some tech companies, and other businesses, are very interested in the emerging so-called grey market. The question is whether and how commercial actors can be held accountable to anyone other than their shareholders. Human rights are often seen as part of corporate social responsibility, but the ageing population is seldom considered part of that equation when it comes to future strategies.

During the last few decades, society has been digitalised in most areas, and digital media have become an important part of citizenship and everyday tasks. Many of the goods and services provided online have been voluntary for people, but as more and more parts of the public sector integrate digital tools, it might become crucial to have a digitally skilled population. What demands can society place on the individual older person and what can the individual claim from society? A wider discussion about media responsibility in different areas could perhaps contribute to enhancing the capabilities of people in later life.

One crucial issue at the macro level is whether regulators can demand more from media corporations without limiting freedom of expression. Regulation versus freedom has been a balancing act for several hundred years and, in the Swedish context, freedom of expression has been highly valued and guarded. Furthermore, who has 
the responsibility to ensure that older citizens have the technological means to act as digital citizens is somewhat unclear. It is a challenge for policymakers to meet these demands, and to encourage media engagement. In an increasingly mediatised environment, we might see an even stronger relationship between the media, health and ageing, which in turn could emphasise the importance of the role of the media in enhancing people's capabilities.

\section{References}

Ayalon, L. (2020). There is nothing new under the sun: Ageism and intergenerational tension in the age of the COVID-19 outbreak. International Psychogeriatrics, 32(10), 1-4. https://doi. org/10.1017/S1041610220000575

Ayalon, L., Chasteen, A., Diehl, M., Levy, B., Neupert, S. D., Rothermund, K., Tesch-Römer, C., \& Wahl, H.-W. (2020). Aging in times of the COVID-19 pandemic: Avoiding ageism and fostering intergenerational solidarity. The Journals of Gerontology: Series B. Psychological Sciences and Social Sciences, 76(2), e49-e52, https://doi-org.ezproxy.ub.gu.se/10.1093/ geronb/gbaa051

Bai, X. (2014). Images of ageing in society: A literature review. Journal of Population Ageing, 7(3), 231-253. https://doi.org/10.1007/s12062-014-9103-x

Bergström, A. (2017). Digital equality and the uptake of digital applications among seniors of different age. Nordicom Review, 38(Special Issue 1), 79-92. https://doi.org/10.1515/ nor-2017-0398

Boulton-Lewis, G. M., Buys, L., Lovie-Kitchin, J., Barnett, K., \& Davis, L. N. (2007). Aging, learning, and computer technology in Australia. Educational Gerontology, 33(3), 253-270. https://doi-org.ezproxy.ub.gu.se/10.1080/03601270601161249

Bravo-Segal, S., \& Villar, F. (2020). Older people representation on the media during COVID-19 pandemic: A reinforcement of ageism? Revista Espanola de Geriatria y Gerontologia. https:// doi.org/10.1016/j.regg.2020.06.002

Buckingham, D. (2003). Media education: Literacy, learning and contemporary culture. Polity Press.

Butler, R. N. (1969). Age-ism: Another form of bigotry. The Gerontologist, 9(4), 243-246. https:// doi-org.ezproxy.ub.gu.se/10.1093/geront/9.4_Part_1.243

Carlsson, U. (Ed.). (2010). Barn och unga i den digitala mediekulturen. Nordicom-Sweden, University of Gothenburg.

Carlsson, U. (2015). Media and information literacy: A crucial element in democratic development. In Media and information literacy: A crucial element in democratic development (pp. 73-78). UNESCO. https://unesdoc.unesco.org/ark:/48223/pf0000232923_ind.locale=en

Carpenter, B. D., \& Buday, S. (2007). Computer use among older adults in a naturally occurring retirement community. Computers in Human Behavior, 23(6), 3012-3024. https://doi. org/10.1016/j.chb.2006.08.015

Coudin, G., \& Alexopoulos, T. (2010). 'Help me! I'm old!' How negative aging stereotypes create dependency among older adults. Aging \& Mental Health, 14(5), 516-523. https://doi-org. ezproxy.ub.gu.se/10.1080/13607861003713182

Couldry, N. (2010). Why voice matters. Culture, politics and neo liberalism. Sage.

Couldry, N. (2019). Capabilities for what? Developing Sen's moral theory for communication research. Journal of Information Policy, 9, 43-55. https://www.jstor.org/stable/10.5325/ jinfopoli.9.2019.0043

Dickinson, A., \& Gregor, P. (2006). Computer use has no demonstrated impact on the well-being of older adults. International Journal of Human-Computer Studies, 64(8), 744-753. https://doi. org/10.1016/j.ijhcs.2006.03.001 
Dolan, J. (2015). Crumbling rejuvenation: Archetype, embodiment and the 'aging beauty myth'. In L. Hockley \& N. Fadina (Eds.), The happiness illusion: How the media sold us a fairytale (pp. 75-88). Routledge.

Edström, M. (2018). Visibility patterns of gendered ageism in the media buzz: A study of the representation of gender and age over three decades. Feminist Media Studies, 18(1), 77-93. https:// doi.org/10.1080/14680777.2018.1409989

Ettema, J. S., Brown, J. W., \& Puepker, R. V. (1983). Knowledge gap effects in a health information campaign. The Public Opinion Quarterly, 47(4), 516-527. https://doi.org/10.1086/268809

Garnham, N. (1997). Amartya Sen's 'capabilities' approach to the evaluation of welfare: Its application to communications. Javnost - The Public, 4(4), 25-34. https://doi.org/10.1080/1318322 2.1997.11008658

Givskov, C. (2017). Growing old with mediatization: Reflexivity and sense of agency. Nordicom Review, 38(Special Issue 1), 79-92. https://doi.org/10.1515/nor-2017-0402

Gullette, M. M. (2017). Ending ageism: Or, how not to shoot old people. Rutger University Press.

Häggkvist, J., \& Rosvall, J. (2020). De äldre, vi andra och Covid-19: En kritisk diskursanalys om äldres framställan $i$ media $i$ samband med Covid-19 rekommendationerna under perioden 16-22 mars 2020 [The elderly, the rest of us and Covid-19: A critical discourse analysis of the portrayal of older people in the media due to the Covid-19 recommendations during the period 16-22 March 2020]. Bachelor's thesis. Ersta Sköndal.

Hargittai, E., \& Hinnant, A. (2008). Digital inequality: Differences in young adults' use of the internet. Communication Research, 35(5), 602-621. https://doi.org/10.1177/0093650208321782

Hartley, J. (1998). Juvenation: News, girls and power. In C. Carter, G. Branston, \& S. Allan (Eds.), News, gender, and power (pp. 47-70). Routledge.

Hjarvard, S. (2013). The mediatization of culture and society. Routledge.

Hjarvard, S. (2017). Mediatization. In P. Rössler (Ed.), The international encyclopedia of media effects. Wiley-Blackwell.

Katz, S. (2001). Growing older without aging? Positive aging, anti-ageism, and anti-aging. Generations, 25(4), 27-32. https://search-proquest-com.ezproxy.ub.gu.se/docview/60100945 ?accountid=11162

Kendall-Taylor, N., Neumann, A., \& Schoen, J. (2020, May 28). Advocating for age in an age of uncertainty: How the COVID-19 crisis is amplifying ageism, and how advocates can push back. Stanford Social Innovation Review. https://ssir.org/articles/entry/ advocating_for_age_in_an_age_of_uncertainty

Kokkinakis, D., Edström, M., \& Berggren, M. (2018, May 2-4). Ageism and Swedish news media. In 24th Nordic Congress of Gerontoloy (NKG).

Kovach, B., \& Rosenstiel, T. (2014). Elements of journalism: What newspeople should know and the public should expect (3rd ed.). Crown.

Kwak, N. (1999). Revisiting the knowledge gap hypothesis: Education, motivation, and media use. Communication Research, 26(4), 385-413. https://doi.org/10.1177/009365099026004002

Levy, B. R., Slade, M. D., Kunkel, S. R., \& Kasl, S. V. (2002). Longevity increased by positive self-perceptions of aging. Journal of Personality and Social Psychology, 83(2), 261-270. https://doi.org/10.1037/0022-3514.83.2.261

Levy, B., Slade, M. D., Chung, P. H., \& Gill, T. M. (2015). Resiliency over time of elders' age stereotypes after encountering stressful events. Journals of Gerontology Series B: Psychological Sciences and Social Sciences, 70(6), 886-890. https://doi-org.ezproxy.ub.gu.se/10.1093/ geronb/gbu082

Livingstone, S. (2008). Internet literacy: Young people's negotiation of new online opportunities. In T. MacPherson (Ed.), Digital youth, innovations, and the unexpected. The John D. and Catherine T. MacArthur Foundation Series on Digital Media and Learning.

Loos, E. (2012). Senior citizens: Digital immigrants in their own country? Observatorio (OBS), 6(1), 1-23. https://doi.org/10.15847/obsOBS612012513

Lundgren, A. S., \& Ljuslinder, K. (2011). Problematic demography: Representations of population ageing in the Swedish daily press. Population Ageing, 4, 165-183. https://doi.org/10.1007/ s12062-011-9048-2 
Lykke Christensen, C. (2017). Healthy ageing and mediated health expertise. Nordicom Review, 38(Special Issue 1), 79-92. https://doi.org/10.1515/nor-2017-0403

McLeod, J. M., Scheufele, D. A., \& Moy, P. (1999). Community, communication, and participation: The role of mass media and interpersonal discussion in local political participation. Political Communication, 16(3), 4-87. https://doi.org/10.1080/105846099198659

Meisner, B. A. (2020). Are you OK, Boomer? Intensification of ageism and intergenerational tensions on social media amid COVID-19. Leisure Sciences, 1-6. https://doi.org/10.1080/0149040 0.2020 .1773983

Ng, R., Allore, H. G., Trentalange, M., Monin, J., \& Levy, B. R. (2015). Increasing negativity of age stereotypes across 200 years: Evidence from a database of 400 million words. PLoS One, 10(2), E0117086. https://doi.org/10.1371/journal.pone.0117086

Nilsson, M., \& Jönson, H. (2009). Äldre i massmedierna - osynliga eller förknippade med problem. In H. Jönsson (Ed.), Åldrande, åldersordning, ålderism. Linköpings universitet.

Nimrod, G. (2020). Changes in internet use when coping with stress: Older adults during the COVID-19 pandemic. American Journal of Geriatric Psychiatry. https://doi.org/10.1016/j. jagp.2020.07.010

Norris, P. (2001). Digital divide: Civic engagement, information poverty and the internet worldwide. Cambridge University Press.

Nussbaum, M. C. (1997). Capabilities and human rights. Fordham Law Review, 66(2), 273-300. https://heinonline.org/HOL/P?h=hein.journals/flr66\&i=289

Nutbeam, D. (2008). The evolving concept of health literacy. Social Science \& Medicine, 67, 2017-2078. https://doi.org/10.1016/j.socscimed.2008.09.050

O'Neil, M., \& Haydon, A. (2015). Aging, agency and attribution of responsibility: Shifting public discourse about older adults. FrameWorks Institute. Retrieved 17 Sept 2020, from https://www.frameworksinstitute.org/publication/ aging-agency-and-attribution-of-responsibility-shifting-public-discourse-about-older-adults/

Obi, T., Ishmatova, D., \& Iwasaki, N. (2013). Promoting ICT innovations for the aging population in Japan. International Journal of Medical Informatics, 82, e47-e62. https://doi.org/10.1016/j. ijmedinf.2012.05.004

Pérez Tornero, J. M., \& Pi, M. (2011). A new horizon: Media literacy assessment and children in Europe. In C. von Felitzen, U. Carlsson, \& C. Bucht (Eds.), New questions, new insight, new approaches: Contributions to the research forum at the world summit on media for children and youth 2010. Nordicom Sweden, University of Gothenburg.

Petäjä, U. (2006). Varför yttrandefrihet? Om rättfärdigandet av yttrandefrihet med utgångspunkt från fem centrala argument $i$ den demokratiska idétraditioner [Why freedom of speech? On the justification of freedom of speech on the basis of five central arguments in the democratic tradition]. Acta Wexionensia 83/2006 (Växjö University).

Potter, W. J. (2005). Media literacy. Sage.

Putnam, R. D. (1993). Making democracy work: Civic traditions in modern Italy. Princeton University Press.

Rains, S. A. (2008). Health at high speed: Broadband internet access, health communication, and the digital divide. Communication Research, 35(3), 283-297. https://doi. org/10.1177/0093650208315958

Reisenwitz, T., Iyer, R., Kuhlmeier, D. B., \& Eastman, J. K. (2007). The elderly's internet usage: An updated look. Journal of Consumer Marketing, 24(7), 406-418. https://doi. org/10.1108/07363760710834825

Robinson, L., Cotton, S. R., Ono, H., Quan-Haase, A., Mesch, G., Chen, W., Schulz, J., Hale, T. M., \& Stern, M. J. (2015). Digital inequalities and why they matter. Information, Communication \& Society, 18(5), 569-582. https://doi.org/10.1080/1369118X.2015.1012532

Schonfield, D. (1982). Who is stereotyping whom and why? Gerontologist, 22(3), 267-272. https://doi.org/10.1093/geront/22.3.267

Seeman, T., Merkin, S., Crimmins, E., Koretz, B., Charette, S., \& Karlamangla, A. (2008). Education, income and ethnic differences in cumulative biological risk profiles in a national sample of US adults: NHANES III (1988-1994). Social Science \& Medicine, 66(1), 72-87. https://doi.org/10.1016/j.socscimed.2007.08.027 
Seifert, A. (2020). The digital exclusion of older adults during the COVID-19 pandemic. Journal of Gerontological Social Work. https://doi.org/10.1080/01634372.2020.1764687

Sen, A. (1985). Commodities and capabilities. Oxford University Press.

Shaker, L. (2014). Dead newspapers and citizens' civic engagement. Political Communication, 31(1), 131-148. https://doi.org/10.1080/10584609.2012.762817

Sweetland, J., Volmert, A., \& O'Neil, M. (2017). Finding the frame: An empirical approach to reframing aging and ageism. FrameWorks Institute.

Torres, S. (2001). Understanding 'successful aging': Cultural and migratory perspectives. Dissertation, Uppsala University.

Torres, S. (2019). Ethnicity and old age: Expanding our imagination. Policy Press.

Trappel, J. (2019). Inequality, (new) media and communications. In J. Trappel (Ed.), Digital media inequalities. Nordicom, University of Gothenburg.

Treré, E., Natale, S., Keightley, E., \& Punathambekar, A. (2020). The limits and boundaries of digital disconnection. Media, Culture \& Society. https://doi.org/10.1177/016443720922054

Tsatsou, P. (2011). Digital divides in Europe: Culture, politics and the Western-Southern divide. Peter Lang.

Tuchman, G. (1978). Introduction: The symbolic annihilation of women in the mass media. In G. Tuchman, A. Kaplan Daniels, \& J. Benet (Eds.), Hearth and home: Images of women in the mass media. Oxford University Press.

Twigg, J. (2013). Fashion and age: Dress, the body and later life. Bloomsbury Academic.

Twigg, J., \& Martin, W. (2015). Routledge handbook of cultural gerontology. Routledge.

United Nations. (2020). Secretary-General's policy brief: The impact of COVID-19 on older persons. http://www.un.org/development/desa/ageing/wp-content/uploads/sites/24/2020/05/ COVID-Olderpersons

van Deursen, A. J. A. M., \& Helsper, E. J. (2015). A nuanced understanding of internet use and non-use among elderly. European Journal of Communication, 30(2), 171-187. https://doi. org/10.1177/0267323115578059

van Deursen, A., \& van Dijk, J. (2014). The digital divide shifts to differences in usage. New Media \& Society, 16(3), 507-526. https://doi.org/10.1177/1461444813487959

Weaver, D. H. (2007). Thoughts on agenda setting, framing, and priming. Journal of Communication, 57(1), 142-147. https://doi.org/10.1111/j.1460-2466.2006.00333.x

Westwood, S. (2019). Ageing, diversity and equality: Social justice perspectives (1st ed.). Routledge.

Wien, C. (2003). Aeldrebilledet i medierna gennem 50 år. Syddanskt universitetsforlag.

Open Access This chapter is licensed under the terms of the Creative Commons Attribution 4.0 International License (http://creativecommons.org/licenses/by/4.0/), which permits use, sharing, adaptation, distribution and reproduction in any medium or format, as long as you give appropriate credit to the original author(s) and the source, provide a link to the Creative Commons license and indicate if changes were made.

The images or other third party material in this chapter are included in the chapter's Creative Commons license, unless indicated otherwise in a credit line to the material. If material is not included in the chapter's Creative Commons license and your intended use is not permitted by statutory regulation or exceeds the permitted use, you will need to obtain permission directly from the copyright holder.

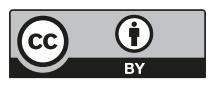

